\title{
AN EXPERIMENTAL STUDY FOR THE EVALUATION OF MATERIALS AND METHODS USED IN THE TREATMENT OF TIN AMALGAM MIRRORS
}

\author{
Dalia A. HASAN ${ }^{i}-$ S. DAWI ${ }^{i i}-$ M. RIFAI ${ }^{i i i}$
}

\begin{abstract}
:
This study aims to evaluate some of the materials and methods proposed for the restoration of amalgam mirrors. The amalgam mirror is the first glass mirrors, where the reflective layer is represented in a layer of mercury and tin amalgamation, formed on a flat glass surface. This layer may reach a severe status of damage which makes it difficult to prevent the change taking place therein, or prevent its continuation and spread. Three different methods of partial and total replacement of corroded/missing areas were investigated to treat and prevent the further destruction of these mirrors. Modern tin amalgam mirror samples were prepared according to the historic manufacturing technique then subjected to artificial aging. The suggested methods of partial replacement were applied onto the samples then subjected again to artificial aging. The performance of these innovative methods was evaluated using Scanning Electron Microscopy (SEM) and the Reflectance spectroscopy (RS).
\end{abstract}

\section{INTRODUCTION}

Mirrors made of glass backed with a reflective coating of tin-mercury amalgam, commonly called the amalgam mirror, were dominant from the sixteenth century until the beginning of the twentieth century. It is therefore the most common type found in museums and in historic buildings ${ }^{1}$. The first known center for the production of tin amalgam mirrors was established by the Dal Gallo brothers in 1507 in Venice ${ }^{2}$.Some of the important and limited studies that have to study and dating archaeological amalgam mirrors was done by Hadsund ${ }^{3}$, (Herrera et al.), ${ }^{4}$ and (Angelini et al. $)^{5}$. All were using a scanning electron microscope coupled with Enerjey dispersive X-Ray spectrometer (SEM-EDS), X-ray diffraction (XRD), X-ray photoelectron spectroscopy (XPS) and infrared spectroscopy (FTIR). Furthermore, deep studies carried out by ((Zywitzki et al. $)^{6}$, to determine the content of tin and mercury in two different phases. Finally, some of the experiments carried by (Torge) ${ }^{7}$ suggested some ways to reduction of mercury emissions resulting from the mirrors. The tin amalgam mirrors were made by sliding glass over tin foil, which was flooded with mercury, forming the reflective layer. This layer of tin amalgam is a binary alloy of tin and mercury forming two different phases: a mercury-rich liquid phase and a tin-rich solid phase ${ }^{9}$.The solid phase is composed of mercury $(20 \% \mathrm{wt})$ and tin $(80 \% \mathrm{wt})$, while the surrounding liquid phase consists of mercury $(95-100 \%)$ and tin $(0-5 \%)^{10}$.

However, this amalgam layer is unstable and changing over time where the mercury gradually evaporates slowly, the liquid phase migrates to the bottoms of displayed vertically mirrors ${ }^{11}$, and the solid phase crystals grow causing tiny voids between

i_iii Faculty of Arcaheology, Cairo University (Egypt) 
amalgam and glass and corrode. Corrosion of the amalgam produces tin dioxide (cassiterite- $\mathrm{SnO}^{2}$ ) and tin monoxide (romarkite- $\mathrm{SnO}$ ) with a consequent decrease of the amalgam adhesion to the glass. This degradation phenomenon leads to reduction or disappearance of the mirror's reflective power ${ }^{12}$. Mercury-tin mirror may show a tendency for a higher concentration of deterioration along the lower half of the mirror, caused by the migrating mercury. This deterioration creates holes of mirroring loss and a darkened, speckled appearance where the spaces between the metallic crystals become larger and more visible ${ }^{13}$. For the preservation of tin amalgam mirrors, several studies recommend a controlled environment -stable temperature and relative humidity- and careful handling. But none propose rational methods for their conservation. In this study different methods of partial and total replacement of corroded/missing areas were suggested. Modern tin amalgam mirror samples were prepared according to the historic manufacturing technique then subjected to artificial aging. The suggested methods of partial replacement were applied onto the samples. These were then artificially aged then studied and evaluated using Scanning Electron Microscopy (SEM) and the Reflectance spectroscopy (RS).

\section{EXPERIMENTAL (Materials and Methods) :}

\subsection{Preparation of the experimental amalgam Mirror samples:}

Model samples of tin amalgam mirrors were prepared by the method described by (Hadsund $)^{14}$ and (Herrera) $)^{15}$. Experiments performed by Hadsund [1] to determine the optimum thickness of the tin foil using $0.1,0.03$, and $0.013 \mathrm{~mm}$ thick tin foil showed that the $0.1 \mathrm{~mm}$ foil ensured the best results. For each experiment a set of three samples was prepared as follows: Tin was obtained in the form of metal sheets, rolled to the desired thickness $(0.1 \mathrm{~mm})$. The mercury used was almost free of impurities $(99.99 \%)$. Eighteen flat samples of $(3-4 \mathrm{~mm})$ thick glass measuring $3 \times 3 \mathrm{~cm}$ were prepared. The glass samples were washed with distilled water and alcohol in order to remove any impurities which could prevent good adhesion between the glass and the metal background and then dried with acetone (Fig.1A). The rolled tin foil was cleaned to remove dark tarnish stains that may cause dark spots on the produced mirror (Fig.1B), and then cut to the same dimensions as the glass samples (Fig.1C). Liquid mercury was slowly poured onto the surface of the tin foil to the thickness of $(\sim 2-3 \mathrm{~mm})$ (Fig.1D). Once the mercury is in contact with tin, the amalgamation process begins directly, which appears as viscous dark spots as shown in (Fig.1E). Then, a second glass sheet was slid slowly in a single smooth movement over the mercury layer to create a homogeneous adhesion on the whole glass surface. Placing the glass suddenly on the surface of the mercury might cause mercury drops to accumulate (get trapped) between the glass surface and tin, which might prevent the occurrence of the complete amalgamation process (Fig.1F). When the glass is in place over the tin foil it was pressed down to make a firm contact between glass and $\operatorname{tin}^{16}$ and to remove the excess mercury. This was done using paper clips to ensure good contact (fig.1G).The clips were removed after 24 hours which is the time for a complete conversion of tin to tin- mercury compound ${ }^{17}$. The mirrors were left to dry for 15 days, first in a horizontal position and then in an oblique position to remove the excess mercury according $^{18}$. This hardening process takes up to a month, depending on the size of the mirror (Fig.1H). 

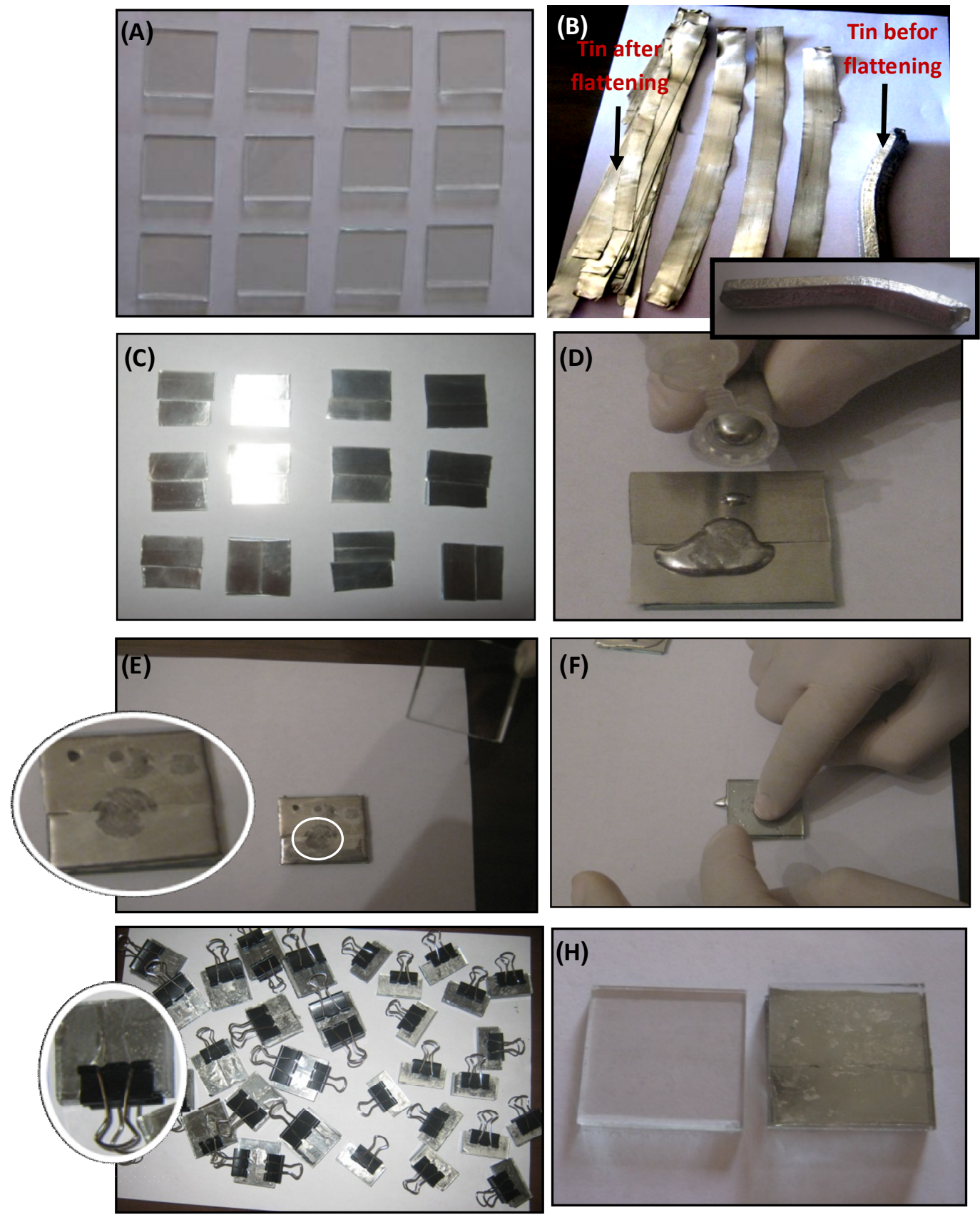

Fig.1.Preparation of experimental amalgam mirror samples :A. glass square samples have been prepared and cleaned;B. Tin rolling and flattening into longitudinal slices ;C.Placing the tin slices on the glass squares; D.Pouring liquid mercury on the tin; E.Darker spot appear once put the mercury on the tin; F.Press slowly the glass square after laying the glass on the mercury; G.Put clips for strong bonding; H.Square glass and resulting mirror.

\footnotetext{
- 42 - An Experimental Study For The Evaluation Of Materials And Methods
} 


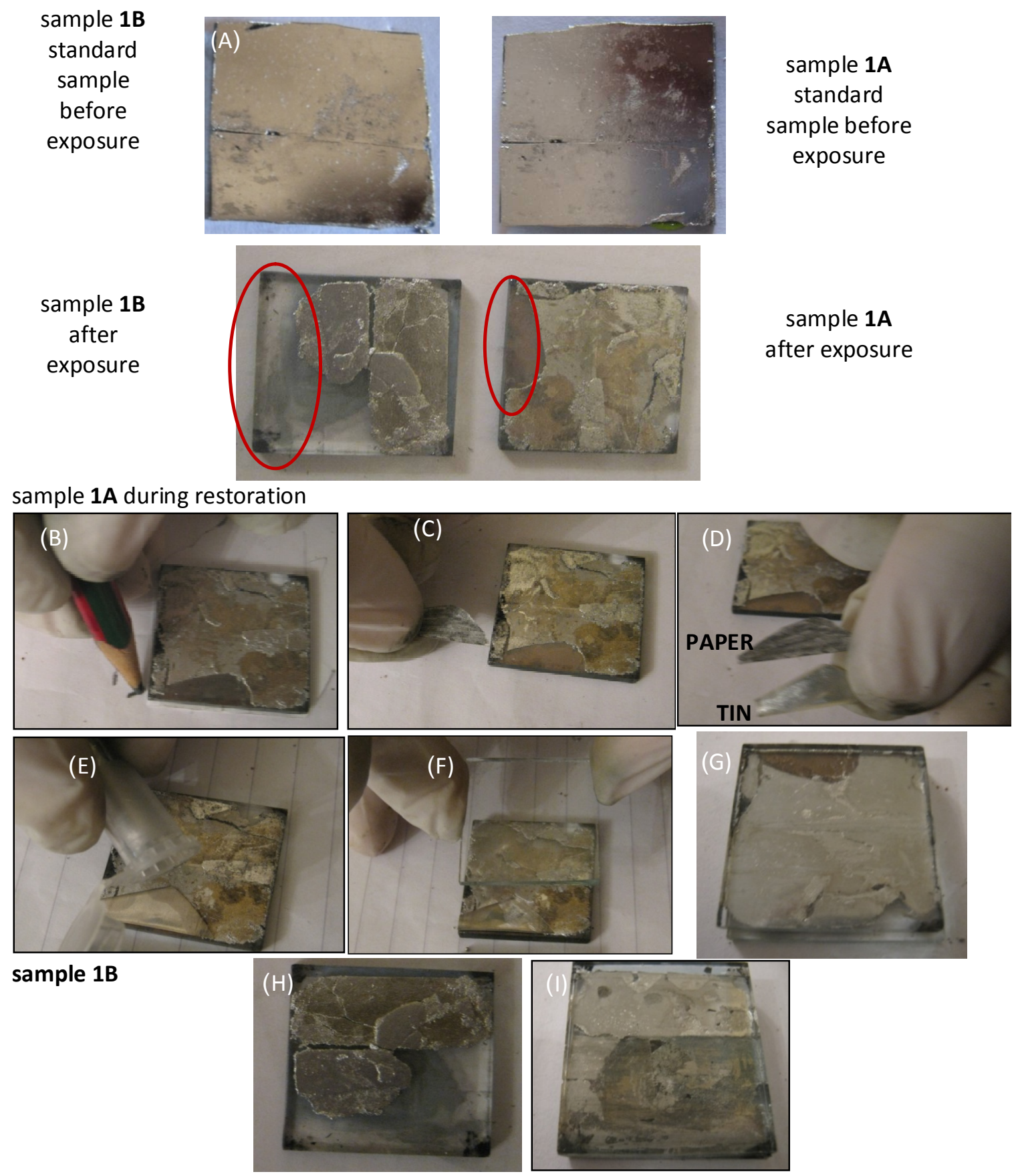

Fig.2. Method of Partial Completion by placing a new layer of tin and mercury :A. two experimental samples that had to be restored(before and after exposure) ;B. take the dimensions and shape of the missing part or the part to be replaced ;C. Cut such drawn of the same shape and dimensions of the missing part from paper; D. cut the tin in the same format; E.pouring the mercury; F. putting the upper sheet of glass on the mercury.; G.experimental mirror after had restored; H.sample 1B befor restoration;I. sample 1B after restoration.

\subsection{Artificial aging}

In this study, the model samples were exposed in a BINDER, Model / Type: 9240300002000, NIS-PMIL-NIS-11 climatic chamber. Before the artificial aging, the 
samples were photographed and characterized using different analytical techniques for comparison purpose with the results obtained after the aging. The same conditions and parameters set by (Arizio, E., et al.) ${ }^{19}$, were used which include;

- Exposure at a temperature of $60^{\circ} \mathrm{Cand} 60 \%$ relative humidity for 24 hours.

- Exposure at a temperature of $80{ }^{\circ} \mathrm{C}$ and $80 \%$ relative humidity for a period of 120 hours.

Then after the application of different repair methods, they were exposed again to the same conditions to evaluate the methods used.

\subsection{Methods of Examination and Analysis:}

Evaluation of the replacement methods was performed using Scanning Electron Microscope (SEM) (Model Philips XL 30, with accelerating voltage $30 \mathrm{KV}$, magnification $10 \mathrm{x}$ up to $400.000 \mathrm{x}$ and resolution for W. $(3.5 \mathrm{~nm})$ that its images allowed to follow samples at all stages. Spectrophotometer (3100 spectrophotometer using color EYE R) was used to measure the reflectivity of samples and to evaluate both the progressive color change of the amalgam layer and the formation of degradation compounds of amalgam.

\section{EXPERIMENTAL TRIALS:}

Three different methods of replacement of missing or deteriorated areas were studied. These include [a] Partial replacement by introducing a new layer of tin and mercury, [b] Partial replacement using dental Amalgam, [c] Partial replacement by re- amalgamation. These methods can be used whenever there is a partial loss in the amalgam layer or if this layer suffers from loss of visibility or frailty. Moreover, they can also assist in hindering the spread of corrosion from the damaged areas.

\subsection{Partial replacement by introducing a new layer of tin and mercury:}

To determine the shape and size of the missing areas to be amended, samples $(\mathbf{1 A}, \mathbf{B})$ (Fig.2A-I) were placed on a sheet of paper over a light-box. Precise measurements and required dimensions were then traced from paper to the tin sheet to produce a perfect match (Fig.2B, C). The tin sheet was cut (Fig.2D) and placed onto the missing area, and then mercury was added (Fig.2E).The second sheet of glass was then placed and the sample inclined (Fig.2F) to get rid of excess mercury. The sample was secured using paper clips and left until amalgamation took place (Fig.2G).

\subsection{Partial replacement using dental Amalgam:}

This method was applied to the experimental samples (2A, B) shown in (Fig.3A) where there is a partial loss obvious in both of them. This method has been applied as follows Fig.3: Dental amalgam is available in the form of a small tube (Fig.3B), internally divided into two parts (Fig.3C), one containing mercury, while the other contains a mixture of [silver (40-70\%), tin (15-30\%), and copper (10-30\%) and a traces of zinc] in the powder form. The two components are mixed together in a glass container using a glass rod (Fig.3C). Better results are achieved using a dental amalgamator. Amalgam formation is evident in the gradual increase of the size of the mercury drop mixed with the metal powder (Fig.3D, E). The mixture is poured immediately onto the missing area of the amalgam layer in the mirror, then, a sheet of glass is placed on top, and secured using paper clips (Fig.3F).

\footnotetext{
- 44 - An Experimental Study For The Evaluation Of Materials And Methods
} 
sample $\mathbf{2 A}$

standard sample before exposure

sample $\mathbf{2 A}$ after

exposure
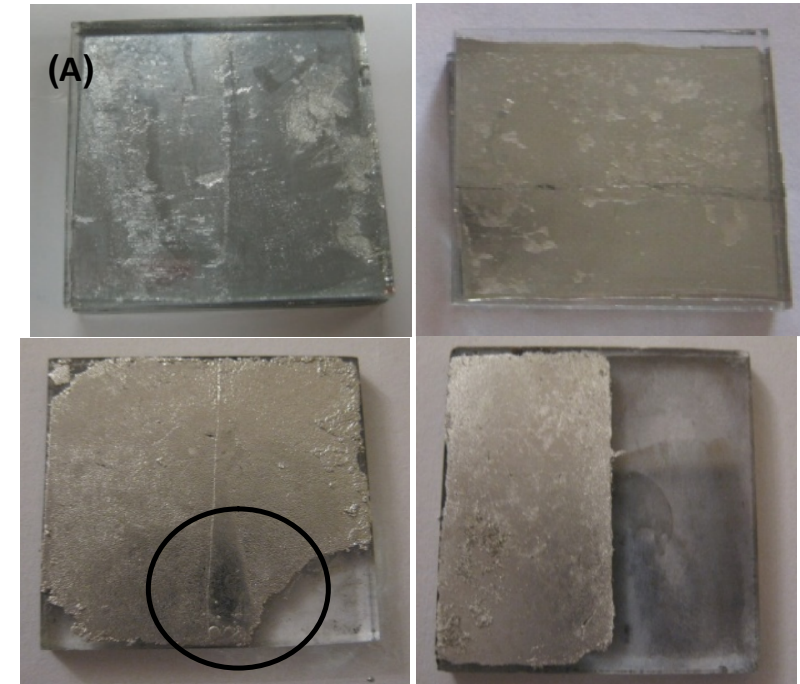

sample 2B

standard sample

before exposure

sample 2B after exposure

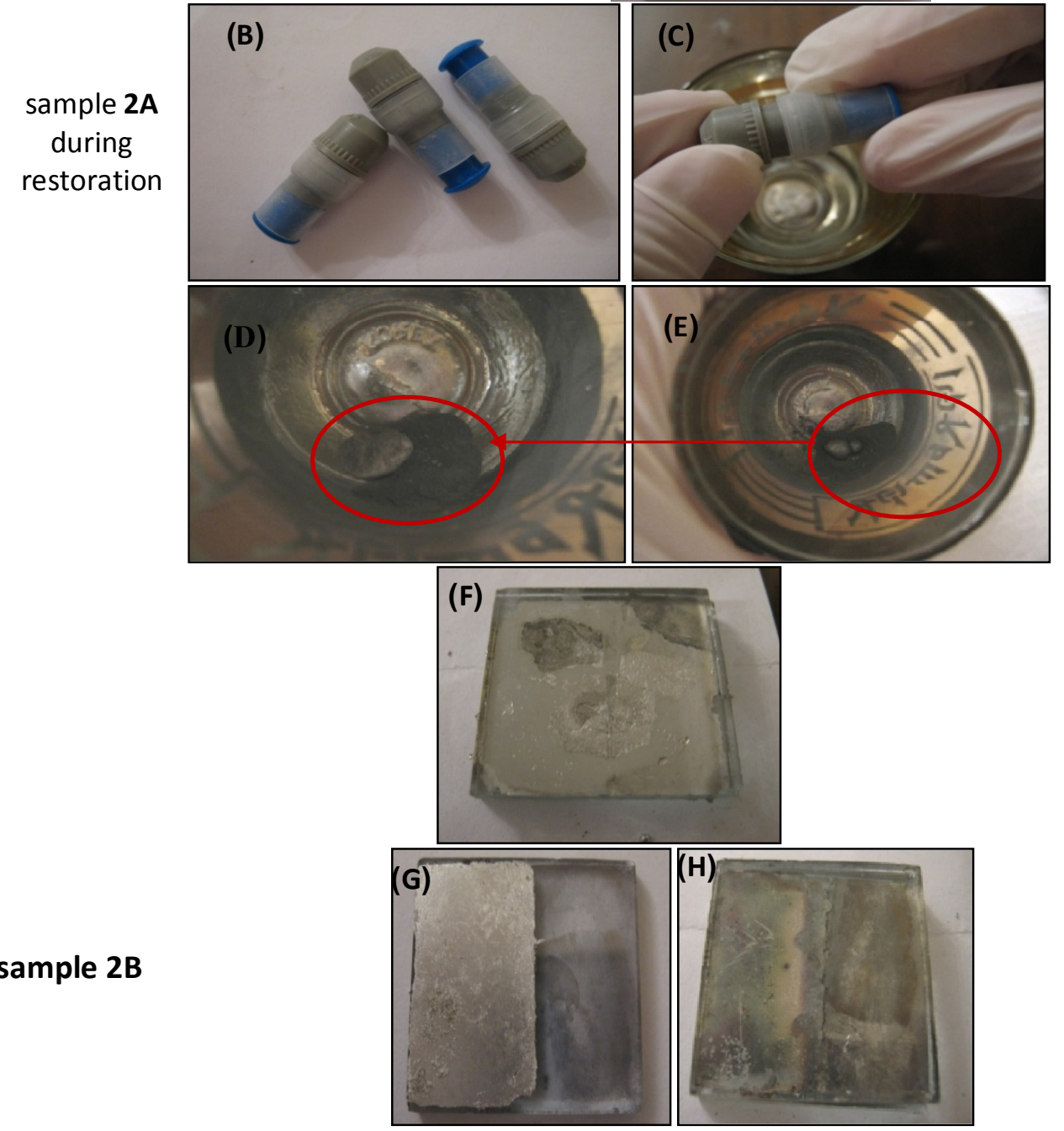

Fig.3. Method of Partial Completion by dental amalgam :A. Experimental sample that selected to be restored ;B. Teeth amalgamation tubes;C. Opening teeth amalgamation tube to put powder in cup; D,E. Gradual increasing in the size of the mercury drop getting mixed with the powder even amalgamation occurrence. ; F. Final form of the restored mirror with the dental amalgam.; G. the sample 2B before restoration.; H. sample 2B after restoration. 


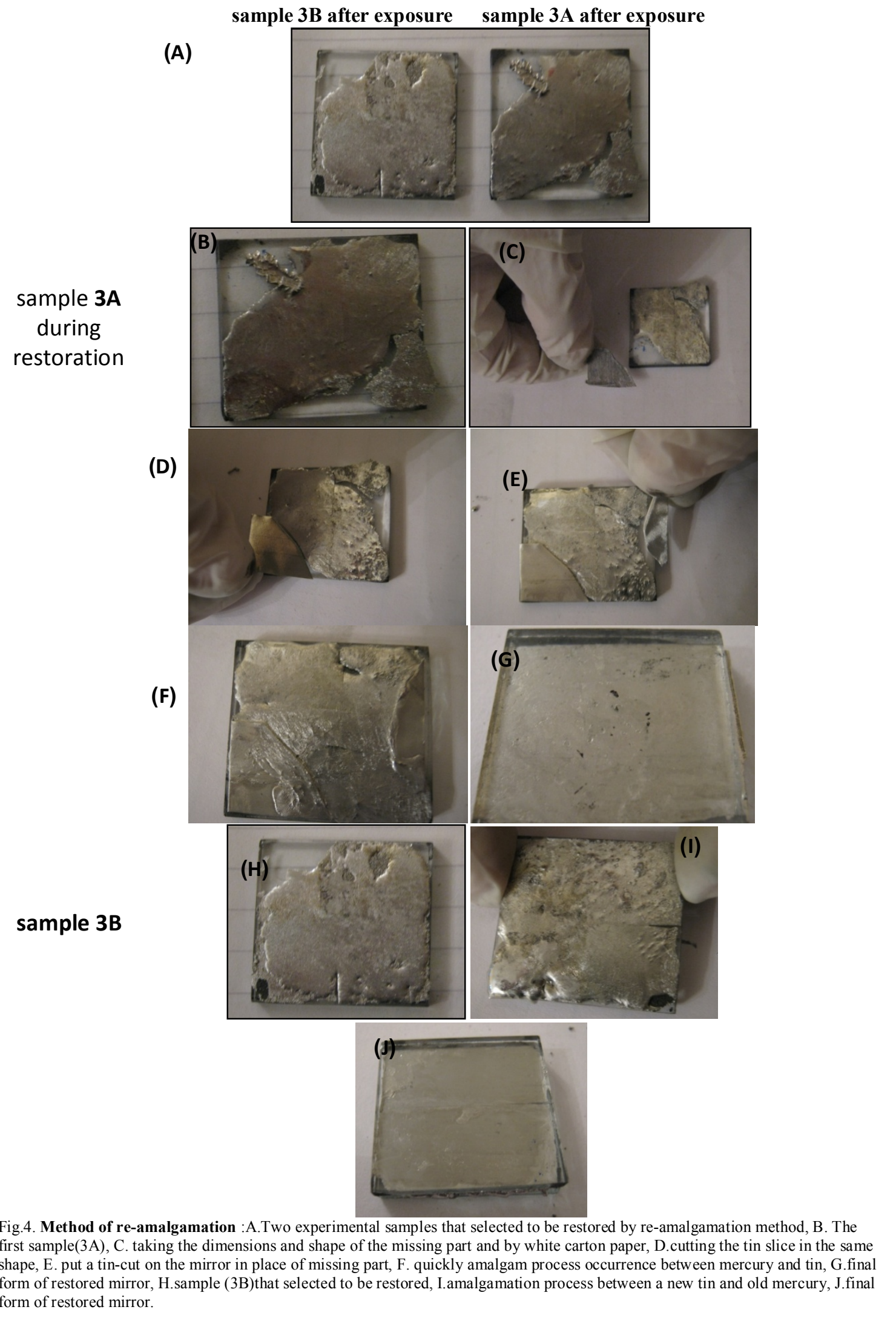

- 46 - An Experimental Study For The Evaluation Of Materials And Methods 


\subsection{Partial replacement by Re-amalgamation:}

This method is used in the case of the presence of residues of liquid mercury, which may be found sometimes in historical amalgam mirrors due to the excessive use of mercury. This mercury remains to exist throughout the life of the mirror trapped between the glass surface and metal or wooden support. These mercury residues can be used in reamalgamation as follows (Fig 4): the mirror to be restored (Fig.4A, B) is placed on white paper to trace precise measurements and required dimensions and then traced from paper to the tin sheet to produce a perfect match. The tin sheet is cut and placed onto the missing area, (Fig.4C, D, E). Once the tin is placed into position an onset of the process of amalgamation begins, (Fig.4F), a glass slide is placed over the mercury diagonally as previously stated and secured using paper clips. (Fig. 4H).

\section{RESULTS:}

\subsection{Partial replacement by introducing a new layer of tin and mercury:}

\begin{tabular}{|c|c|c|c|c|}
\hline Standard & $\begin{array}{c}\text { Sample Before } \\
\text { Restoration (After } \\
\text { Exposure) }\end{array}$ & $\begin{array}{c}\text { Sample After } \\
\text { Restoration }\end{array}$ & $\begin{array}{c}\text { Sample After } \\
\text { Exposure } \\
\text { (For Restoration } \\
\text { Evaluation) }\end{array}$ \\
\hline 1B & & & & \\
\hline
\end{tabular}

Visual examination revealed dimness and darkness in the replaced area. This was evident as soon as the mercury was poured over the tin in the missing region, most probably due to a reaction between the old and new layers. The added mercury interacted with the original amalgam layer causing dimness which spread rapidly in the replaced areas, and darkened more after exposure. 


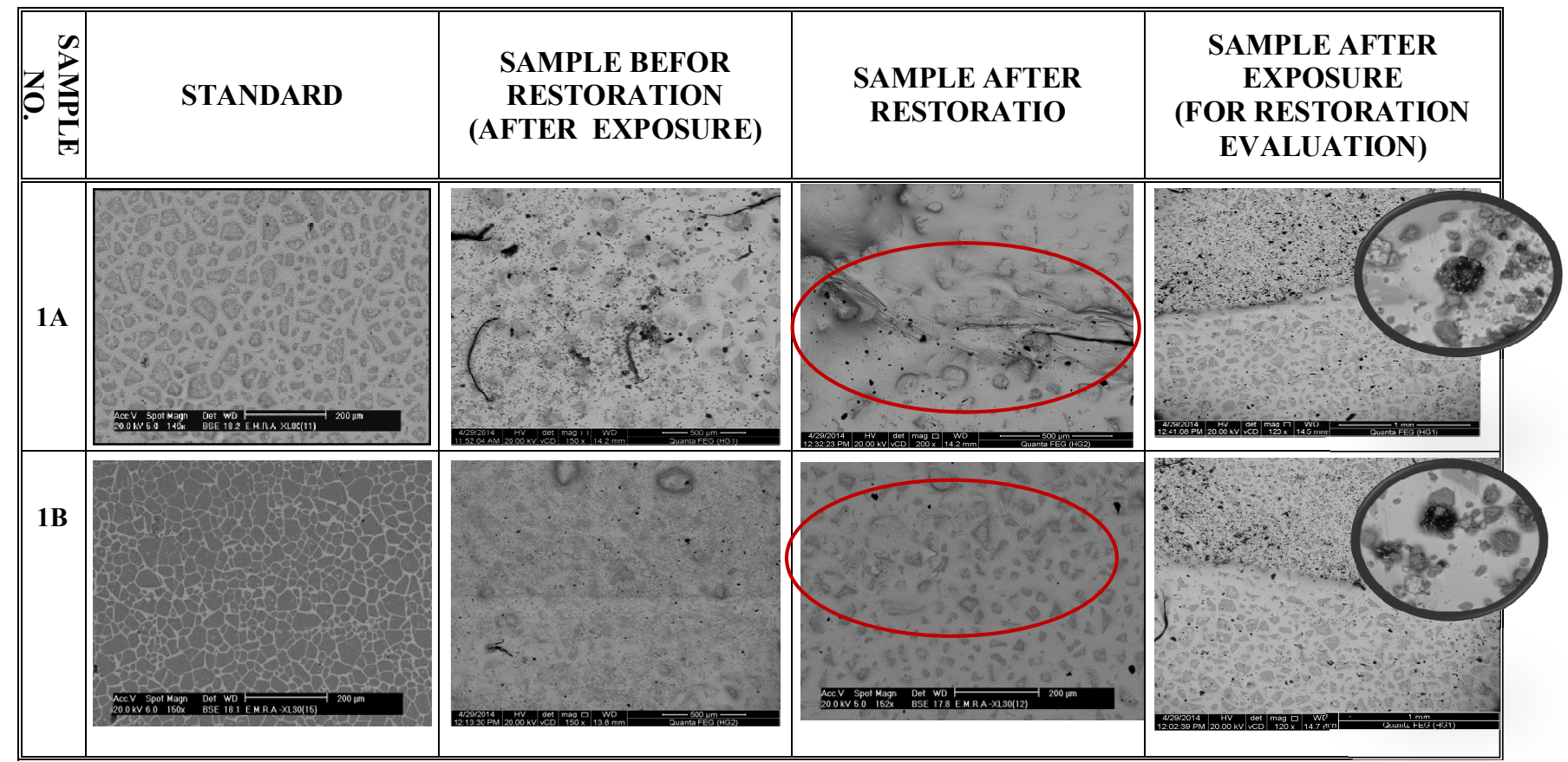

Fig.6.Evaluation of the restoration by the Method of Partial Completion with a new layer of tin and mercury (SEM microscope)

SEM examination of the standard sample before exposure to artificial aging showed (Fig.6) consistency in the sample texture and the presence of two different phases, a liquid phase (lighter in color) and crystals of a solid phase and the absence of any abnormalities or dark spots. However, after exposure to artificial aging, the emergence of black spots, and pits were detected. After the application of partial replacement, a continued spread of these black spots occurred along with deformation in the texture of the sample and the lack of satisfactory bonding between the two layers. Results of the color spectrophotometer as shown in table (1) showed that the reflectivity of the standard sample directly after manufacture was $(77.56 \%)$, while after exposure to accelerated aging reached $(55.22 \%)$. After restoration, the reflectivity increased again slightly reaching $(58.30 \%)$. This is an evidence of the inefficiency of this method, that as soon as it has been applied, there was a color change and dimness caused lack of reflection. Moreover, the degree of reflectivity has changed to reach $(32.44 \%)$ after exposure. This method showed unsatisfactory results.

Table (1) Evaluation of the partial replacement method by introducing a new layer of tin and mercury with colour spectrophotometer

\begin{tabular}{|c|c|c|c|c||}
\hline $\begin{array}{c}\text { SAMPLE } \\
\text { NO. }\end{array}$ & STANDARD & $\begin{array}{c}\text { SAMPLE BEFOR } \\
\text { RESTORATION (AFTER } \\
\text { EXPOSURE) }\end{array}$ & $\begin{array}{c}\text { SAMPLE } \\
\text { AFTER } \\
\text { RESTORATION }\end{array}$ & $\begin{array}{c}\text { SAMPLE AFTER } \\
\text { EXPOSURE } \\
\text { (FOR } \\
\text { RESTORATION } \\
\text { EVALUATION) }\end{array}$ \\
\hline \hline $1 \mathrm{~A}$ & $77.56 \%$ & $\% 55.22$ & $58.30 \%$ & $32.44 \%$ \\
\hline $1 \mathrm{~B}$ & $75.44 \%$ & $\% 56.37$ & $59.33 \%$ & $33.12 \%$ \\
\hline
\end{tabular}

- 48 - An Experimental Study For The Evaluation Of Materials And Methods 


\subsection{Partial replacement using dental Amalgam:}

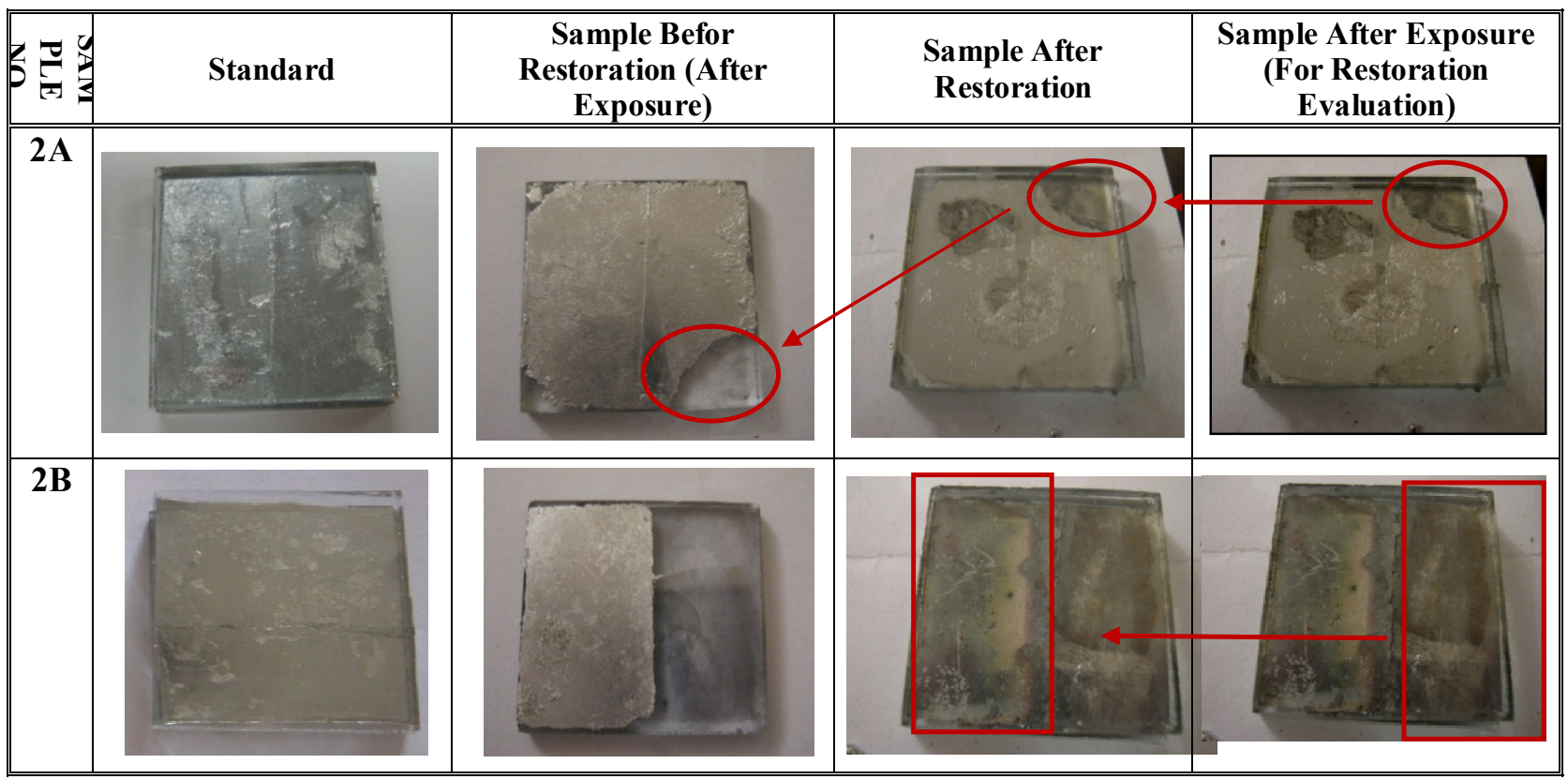

Fig.7. Evaluation of Partial Completion with dental amalgam (Photography) visual examination

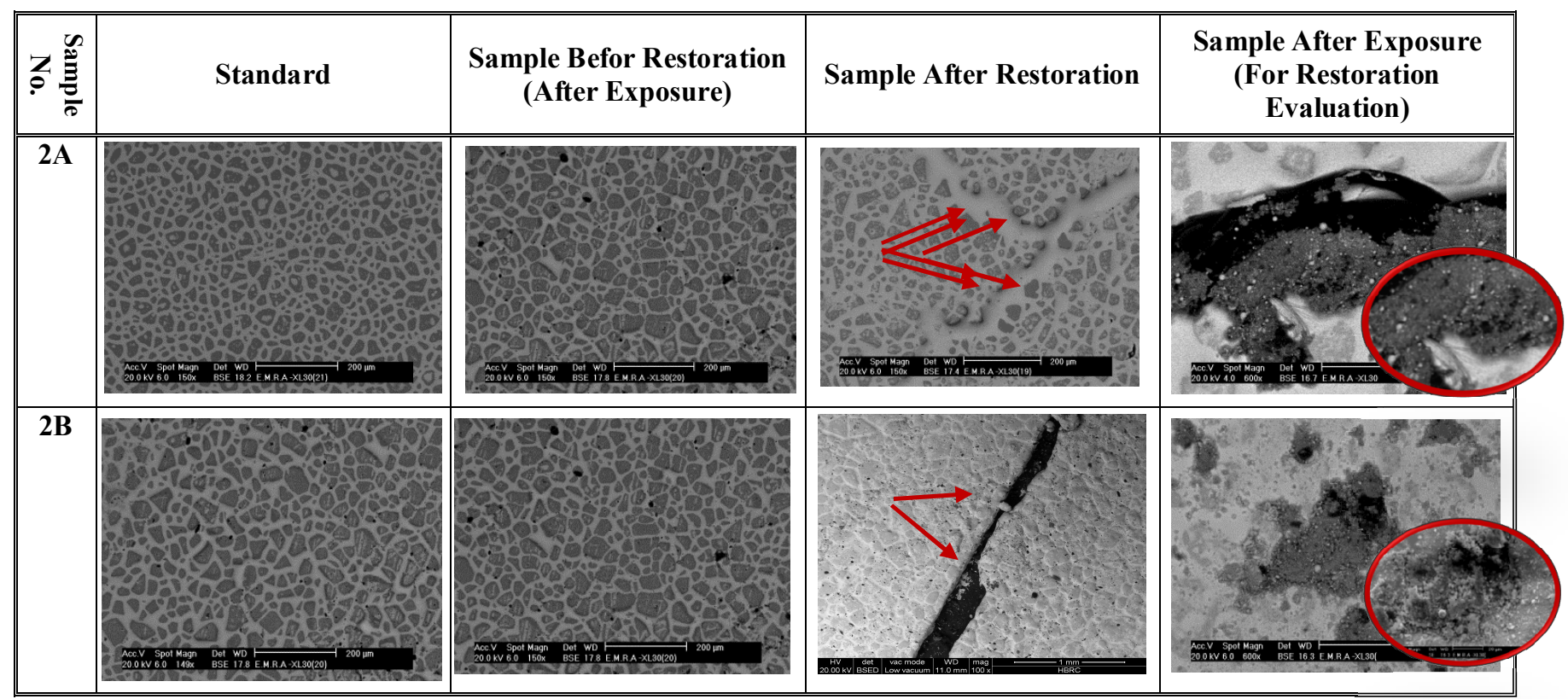

Fig.8. Evaluation of the Partial Completion with dental amalgam (SEM microscope)

Visual examination (Fig.7) showed dimness and darkness in the replaced area, which was evident immediately after using the dental amalgam which is probably due to the interaction of the components of the dental amalgam with the old layer (tin and mercury) 
causing the formation of oxides that resulted in color changes for both old and new layers (2A, 2B).

SEM-EDS examination (Fig.8) demonstrated a consistency in the sample texture and the absence of impurities. After exposure, some tiny black spots appeared, and multiplied after the application of dental amalgam. There was no fusion or good bonding between the two layers which led to the appearance of cracks and formation of new compounds in the form of conglomerates, indicative of the inefficiency of this method as well.

\section{Table (2) Evaluation of the Partial replacement using dental amalgam with colour spectrophotometer}

\begin{tabular}{||l|l|l|l|l||}
\hline $\begin{array}{c}\text { Sample } \\
\text { No. }\end{array}$ & Standard & $\begin{array}{c}\text { Sample Before } \\
\text { Restoration (After } \\
\text { Exposure) }\end{array}$ & $\begin{array}{c}\text { Sample After } \\
\text { Restoration }\end{array}$ & $\begin{array}{c}\text { Sample After } \\
\text { Exposure } \\
\text { (For Restoration } \\
\text { Evaluation) }\end{array}$ \\
\hline \hline 2A & $72.45 \%$ & $\% 53.32$ & $44.34 \%$ & $23.09 \%$ \\
\hline 2B & $70.03 \%$ & $\% 57.59$ & $42.98 \%$ & $22.12 \%$ \\
\hline
\end{tabular}

(Table.2) shows that the reflectivity of the standard sample was as high as $72.45 \%$, while after exposure to accelerated aging reached $53.32 \%$. After a restoration, the reflectivity dropped to $44.34 \%$ and dropped even further to $23.09 \%$ after exposure, giving unsatisfactory results.

\subsection{Partial replacement by re-amalgamation}

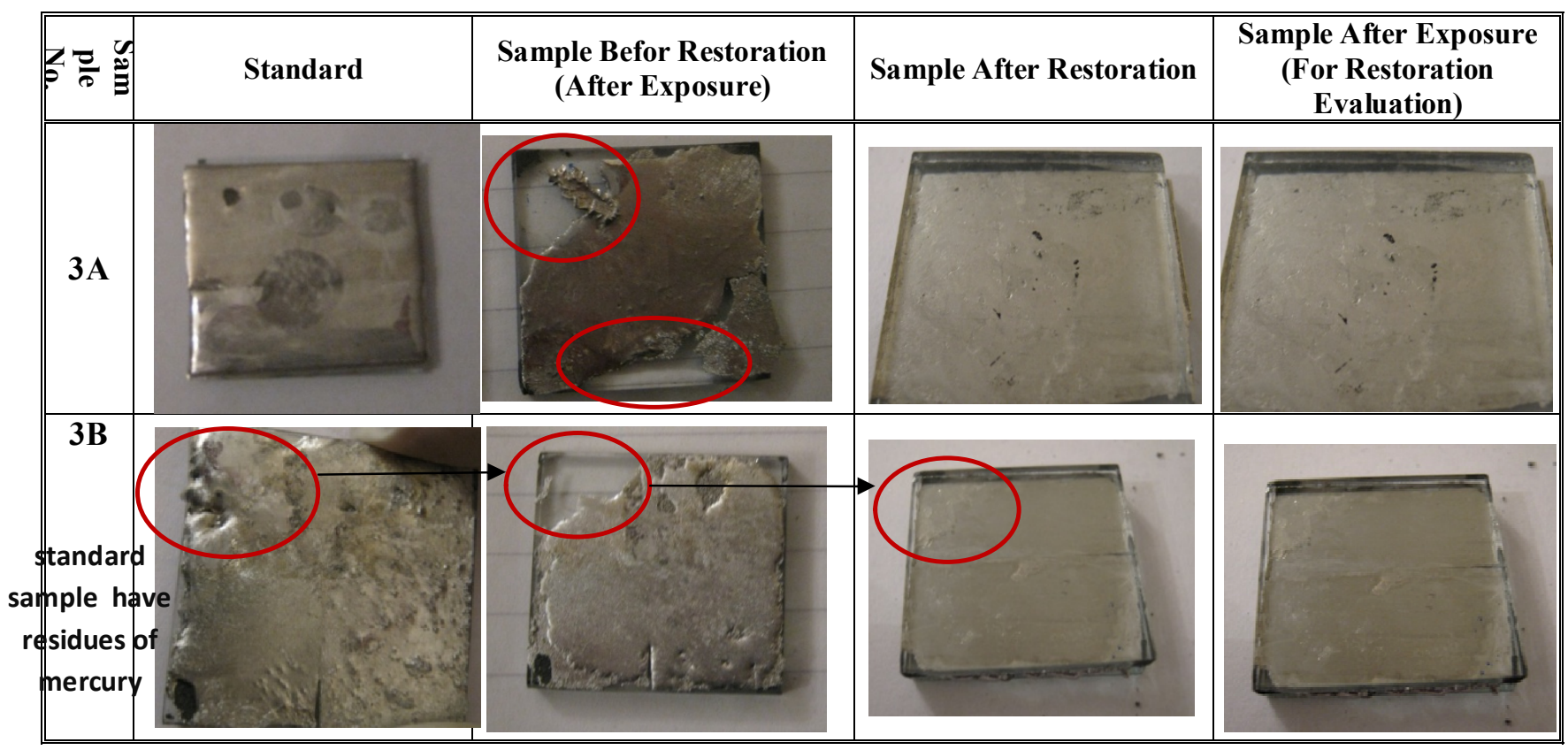

Fig.9. Evaluation of Partial Completion by re-amalgamation process (Photography) visual examination.

\footnotetext{
- 50 - An Experimental Study For The Evaluation Of Materials And Methods
} 
Visual examination (Fig.9) showed that the results were satisfactory as only slight color change occurred in the replaced areas, moreover, there was an excellent uniformity between the old and new layer and the interface between the two layers was not evident.

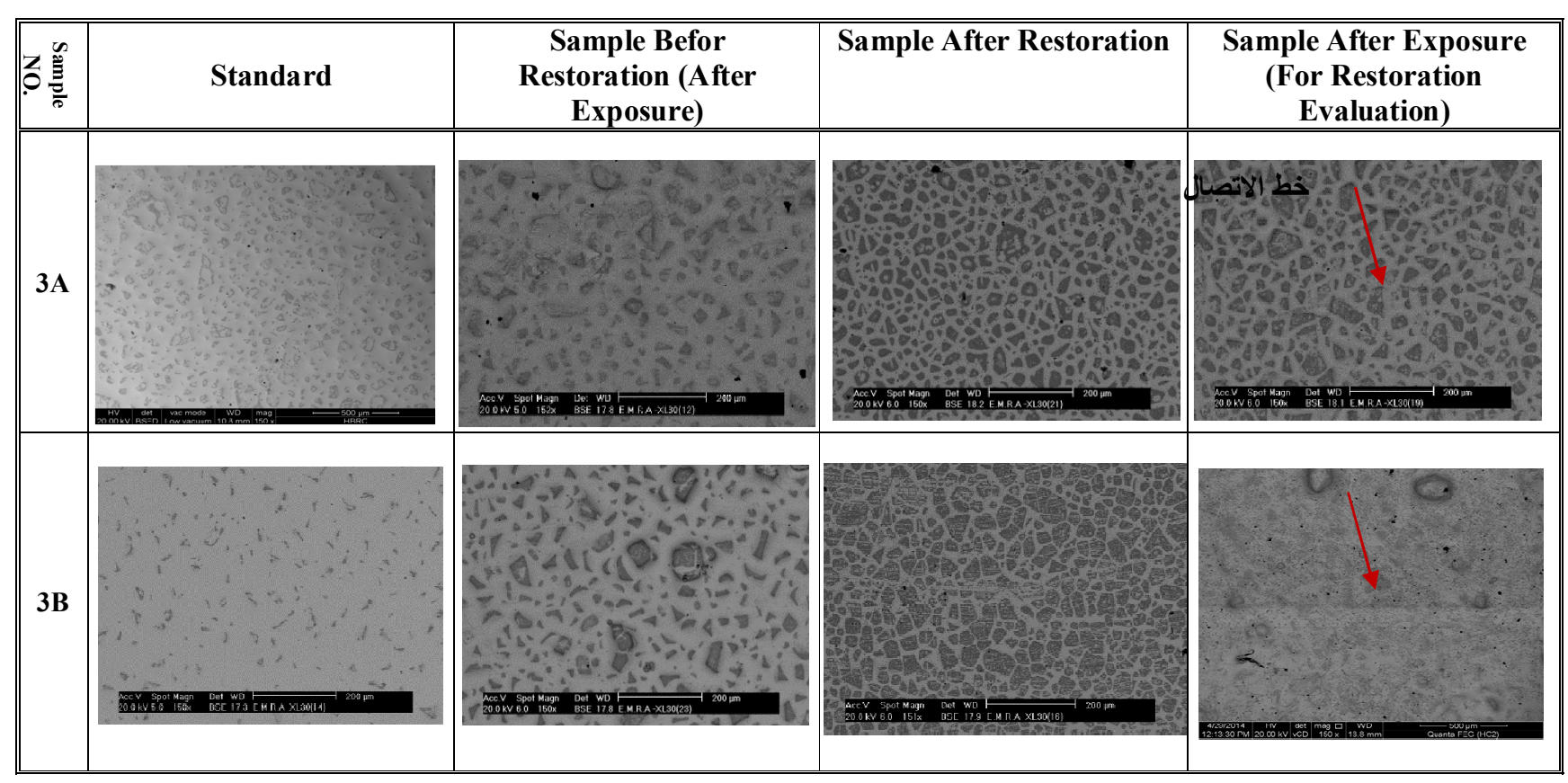

SEM-EDS examination showed that there was consistency between the solid and liquid phase crystals with an increase in the area of the liquid phase in the form of uncombined mercury. After exposure evaporation of some of the excessive mercury occurred with growth of the solid phase crystals and there is satisfactory interaction between the old and new amalgam layers with no evident interface line between these layers. Therefore this method is recommended in the case of the presence of residues of mercury in the background of the mirror.

Table (3) Evaluation of the Partial replacement method by re-amalgamation with colour spectrophotometer

\begin{tabular}{||l|l|l|l|l||}
\hline $\begin{array}{c}\text { SAMPLE } \\
\text { NO. }\end{array}$ & STANDARD & $\begin{array}{c}\text { SAMPLE BEFOR } \\
\text { RESTORATION } \\
\text { (AFTER } \\
\text { EXPOSURE) }\end{array}$ & $\begin{array}{c}\text { SAMPLE AFTER } \\
\text { RESTORATION }\end{array}$ & $\begin{array}{c}\text { SAMPLE AFTER } \\
\text { EXPOSURE } \\
\text { (FOR } \\
\text { RESTORATION } \\
\text { EVALUATION) }\end{array}$ \\
\hline \hline $3 \mathrm{~A}$ & $74.45 \%$ & $\begin{array}{l}7.01 \% \\
\text { (in missing part) }\end{array}$ & $72.35 \%$ & $69.22 \%$ \\
\hline 3B & $71.09 \%$ & $\begin{array}{l}6.33 \% \\
\text { (in missing part) }\end{array}$ & $70.03 \%$ & $67.35 \%$ \\
\hline
\end{tabular}


As shown in (Table.4) the reflectivity of sample (3A) before the exposure was $(74.45 \%)$ and after exposure to accelerated aging was (7.01\%) in the missing areas. After restoration the reflectivity increased to $(72.35 \%)$ and after exposure the decrease in reflectivity was minimal reaching $(69.22 \%)$. The second sample (3B) confirmed the results showing great stability of this method.

\section{CONCLUSION:}

In this study three different methods of restoring partially and completely deteriorated tin amalgam backing in historic mirrors were investigated. The first method of partial replacement of amalgam layer did not give satisfactory results due to the lack of interaction between the old and replaced layers, moreover the reflection in the replaced area was very low (blackout spots) and therefore this method was excluded. The second method of partial replacement using dental amalgam was also excluded due to the deformities in amalgam layer and lack of crystalline consistency, along with lack of good interaction between the two layers. The method of partial replacement by reamalgamation in which the residues of liquid mercury found trapped in archaeological amalgam mirrors were used to complete the missing areas gave satisfactory results. There was satisfactory interaction between the old and new amalgam layers with no evident interface line between these layers. But one of the disadvantages of this method is that it is used only in the case of the presence of residues of Mercury in the background of the mirror. 


\section{NOTES:}

${ }^{1}$ Hadsund, P., “The tin-mercury mirror: Its manufacturing technique and deterioration processes”, Studies in Conservation 38 (1993), 3-16.

${ }^{2}$ Herrera, L.K, Duran A., Franquelo M.L., Jimenez de Haro M.C., Justo Erbez A., Perez-Rodriguez, J.L., "Studies of deterioration of the tin-mercury alloy within ancient Spanish mirrors", Journal of Cultural Heritage 9 (2008), e41-e46.

${ }^{3}$ Hadsund, P., Studies in Conservation 38 (1993), 3-16.

${ }^{4}$ Herrera, L.K, Duran A., Franquelo M.L., Jimenez de Haro M.C., Justo Erbez A., Perez-Rodriguez, J.L., Journal of Cultural Heritage 9 (2008), e41-e46.

5 Angelini, E., Grassini S., Corbellini S., Parvis M., Piantanida M., “A multidisciplinary approach for the conservation of a building of the seventeenth century", Applied physics 100 (2010), 763-769.

${ }^{6}$ Zywitzki, O., Nedon W., Kopte T., Modes T., "Characterization of baroque tin amalgam mirrors of the historic Green Vault in Dresden", Applied physics A, 92 (2008), 123-126.

${ }^{7}$ Torg M., Krug, S., Buecker M., Scharf H., Witthuhn H., "Reduction of mercury emissions from historical tin mercury mirrors", in Poster Tagung: 9th Indoor Air Quality Meeting (IAQ 2010), Tagungsb and Chalon-sur Soane (2010).

${ }^{8}$ Herrera, L.K., Duran, A., Jimenez de Haro M.C., Perez-Rodriguez J.L., Justo A., "Study of baroque artworks by non-destructive techniques", Coalition Electronic Newsletter 14 (2007),10-14

9 Arizio, E., Orsega E.F., Sommariva G., Falcone R., "Tin amalgam mirrors: investigation by XRF, SEMEDS, XRD and EPMA-WDS mapping”, Applied physics A (2013), 733-745.

${ }^{10}$ Arizio, E., Orsega E.F., Falcone R., Sommariva G., "Artificial aging of tin amalgam mirrors: A preliminary study of alteration compounds and kinetics", Procedia chemistry 8 (2013), 3-10.

${ }^{11}$ Arizio, E., Orsega E.F., Sommariva G., Falcone R., Applied physics A (2013), 733-745.

${ }^{12}$ Herrera, L.K, Duran A., Franquelo M.L., Jimenez de Haro M.C., Justo Erbez A., Perez-Rodriguez, J.L., Journal of Cultural Heritage 9 (2008), e41-e46; Arizio, E., Orsega E.F., Sommariva G., Falcone R., Applied physics A (2013),733-745.

${ }^{13}$ Kathleen, P., Historic mercury amalgam: history, safety and preservation. Williamstown Art Conservation Center, (2010).

${ }^{14}$ Hadsund, P., Studies in Conservation 38 (1993), 3-16.

${ }^{15}$ Herrera, L.K., Duran, A., Jimenez de Haro M.C., Perez-Rodriguez J.L., Justo A., "Study of baroque artworks by non-destructive techniques", Coalition Electronic Newsletter 14 (2007),10-14

${ }^{16}$ Hadsund, P., Studies in Conservation 38 (1993), 3-16.

${ }^{17}$ Hadsund, P., Studies in Conservation 38 (1993), 3-16.

18 Arizio, E., Orsega E.F., Sommariva G., Falcone R., Applied physics A (2013), 733-745.

${ }^{19}$ Arizio, E., Orsega E.F., Falcone R., Sommariva G., Procedia chemistry 8 (2013), 3-10. 